\title{
Versatile photophysiology of compositionally similar cyanobacterial mat communities inhabiting submerged sinkholes of Lake Huron
}

\author{
Michael J. Snider ${ }^{1, *}$, Bopaiah A. Biddanda ${ }^{1}$, Morgan Lindback1 ${ }^{\text {, Sharon L. Grim² }}$, \\ Gregory J. Dick² \\ ${ }^{1}$ Annis Water Resources Institute, Grand Valley State University, Muskegon, MI 49441, USA \\ ${ }^{2}$ Department of Earth and Environmental Sciences, University of Michigan, Ann Arbor, MI 48109, USA
}

\begin{abstract}
Recently discovered submerged sinkholes in Lake Huron are high-sulfur, lowoxygen extreme environments for microbial life. In order to understand the relationship between the physical environment, photophysiology and community composition, we measured the physical conditions, photophysiological indices, and genetic diversity at 3 microbial mat sites bathed in high conductivity groundwater under a natural light gradient during 2012 and 2013. A strong seasonal trend prevailed at all sites, characterized by decreased photosynthetic yield $\left(F_{\mathrm{v}}{ }^{\prime} / F_{\mathrm{m}}{ }^{\prime} ; 0.25\right.$ to 0.40 ) during the summer (April to August) and increased yield (0.70 to 0.75) during the winter (November to March). Chlorophyll a content varied seasonally in a similar manner to photosynthetic yield. All sites were dominated by $>80 \%$ abundance of one cyanobacterial group, most closely related to Phormidium sp. Phycobilins (phycocyanin and phycoerythrin) were consistently higher in concentration than chlorophyll. Photosynthetic yield was statistically indistinguishable between sites, suggesting that these mat communities are able to acclimate across a wide range of photosynthetically active radiation (PAR). Interestingly, these cyanobacteria carried out oxygenic photosynthesis in the presence of in vitro $\mathrm{H}_{2} \mathrm{~S}$, further suggestive of their versatile photophysiologies under variable redox conditions. Collectively, our study provides insight into the adaptive capabilities of cyanobacteria by revealing how they photophysiologically respond to changes in light climate and redox conditions, and are thereby able to inhabit a wide range of physico-chemical environments. Such versatile physiologies may have enabled their ancestors to thrive across a range of habitats on early Earth.
\end{abstract}

KEY WORDS: Cyanobacteria $\cdot$ Sinkhole $\cdot$ Photophysiology $\cdot$ Photopigments $\cdot$ Photosynthesis

\section{INTRODUCTION}

Cyanobacteria occupy a vast range of habitats with varying light intensities and comprise a large portion of microbial life in oceans, lakes, and soils (GarciaPichel et al. 2003). They are often the inhabitants of extreme environments, from permanently icecovered lakes to thermal hot springs (Klatt et al. 2011, Olsson-Francis \& Cockell 2010). With such huge variation in niches filled across the planet, cyanobacteria exhibit an incredibly diverse and

*Corresponding author: snidemic@mail.gvsu.edu expansive evolutionary history, both morphologically and genetically, as they must possess many different life strategies to fill these niches. Common cyanobacterial life strategies include sheath building, mat/biofilm formation, motility, use of heterocysts for nitrogen fixation, and protective pigmentation or changes in photophysiology to make the best use of incident sunlight (Castenholz \& Garcia-Pichel 2012).

Photosynthetic organisms are physiologically dynamic as they must tolerate changes in available solar radiation both daily and seasonally. The cyano-

(C) The authors 2017. Open Access under Creative Commons by Attribution Licence. Use, distribution and reproduction are unrestricted. Authors and original publication must be credited. 
bacteria in this study inhabit relatively extreme conditions and must respond to fluctuating illumination and chemical changes. Tolerating changes in illumination involves changes in pigmentation and photophysiology. Pigment content directly affects photosynthetic yield - when a cell has greater pigment content, more light is absorbed. When too much energy is absorbed, some of it must be released as fluorescence to prevent damage. Thus, constant regulation of pigment levels is vital (Falkowski \& Raven 1997).

Photosynthetic yield $\left(F_{\mathrm{v}}{ }^{\prime} / F_{\mathrm{m}}{ }^{\prime}\right)$ is a non-invasive, instantaneous and integrated measure of several photosynthetic processes that provides a broad measure of quantifying the photosynthetic condition of an organism. Cyanobacteria are oxygenic photosynthesizers, which means they contain both Type I and Type II photosystems (PSI and PSII, respectively). The 2 systems work in concert to strip electrons from water and create a proton gradient to drive ATP synthesis. In addition, in the presence of sulfide, some cyanobacteria can shut down PSII and perform anoxygenic photosynthesis with only PSI. How photosynthetic organisms developed oxygenic photosynthesis as well as a tolerance for sulfide is currently unknown - especially over the early geological period when oxygen was poisonous to the organisms inhabiting the planet. While classified as Cyanobacteria, the organisms in this study are able to conduct both oxygenic and anoxygenic photosynthesis (Falkowski et al. 2008, Biddanda et al. 2009, 2012). This is a rare but previously well-documented phenomenon (Oren 1977, Cohen et al. 1986).

The purpose of this study was to characterize how changes in light intensity, sulfide and oxygen levels affect the photophysiology of cyanobacteria-dominated mats in 3 recently discovered submerged sinkhole ecosystems of Lake Huron across a natural light gradient (94 to $1879 \mu \mathrm{mol} \mathrm{s} \mathrm{s}^{-1} \mathrm{~m}^{-2}$; see Fig. 1 inset; Biddanda et al. 2009). To date, no other studies have analyzed the in vitro pigment content or in situ photosynthetic yield of these microbial mats in the Lake Huron sinkholes (Biddanda et al. 2015). Pigment levels (chlorophyll, phycoerythrin and phycocyanin) as well as photosynthetic yield were measured to understand the photophysiology of these microbial systems using both in situ and in vitro studies. These results were compared with genetic analyses of bacterial community composition at the 3 study sites. Our findings may be helpful in describing the life strategies of sinkhole cyanobacteria that thrive under diurnally and seasonally variable light and redox conditions.

\section{MATERIALS AND METHODS}

\author{
Study sites
}

Lake Huron, the third largest of the Great Lakes, is contained within a basin underlain by 400 million year old Paleozoic limestone bedrock that formed when shallow seas covered these continental areas (Gardner 1974, Grannemann et al. 2000). Some sinkholes can be found on land while others are located under the modern-day surface waters of Lake Huron (Biddanda et al. 2009). In these submerged sinkholes, cold, dense groundwater rich in sulfur, with high conductivity but low oxygen, continuously flows through cracks and underwater springs onto the floor of Lake Huron (Ruberg et al. 2008). Groundwater at all 3 study sites is compositionally similar, and they are therefore thought to have a common aquifer source.

\section{Alpena Library Fountain}

'The Fountain' (FT) is an artesian well located directly next to the Alpena County Library $\left(45^{\circ}\right.$ $3.747^{\prime}$ N, $83^{\circ} 25.872^{\prime}$ W; Fig. 1). Its location between 2 buildings provides shading in the morning and late evening, but due to the absence of any overlying water, direct sunlight reaches the cyanobacteria during midday. Water flows from the top of the fountain into an upper trough, which overflows into a larger bottom basin and then to a single drain. Cyanobacterial mat growth is typically located around the perimeter of the bottom basin, directly on concrete, with no underlying sediment. The mat growth at this site is typically a dense, brown/orange color during the summer months, and a deeper purple color more typical of the other sites during the winter.

\section{El Cajon Bay}

'El Cajon' (EC) is a shallow ( 1 $\mathrm{m}$ ) spring located in a small inlet of El Cajon Bay (45 $5.120^{\prime}$ N, 83 $19.467^{\prime}$ W; Fig. 1). Sulfate-rich groundwater flows up from a vent and quickly mixes with the surrounding oxic waters. Cyanobacterial growth is a deep purple color, and is prevalent inside the vent and up to roughly $3 \mathrm{~m}$ out towards the rest of the bay where purple cyanobacterial growth slowly thins out. Much of the cyanobacterial growth present at this site exists on underwater plants and on the underside of detritus floating at the water surface. 
Fig. 1. Alpena County and Thunder Bay National Marine Sanctuary, Lake Huron, showing location of the 3 study sites as insets on the right side of the figure: (1) Middle Island Sinkhole (MIS, $45^{\circ} 11.927^{\prime} \mathrm{N}$, 83 $\left.19.674^{\prime} \mathrm{W}\right),(2)$ El Cajon (EC, $45^{\circ} 5.120^{\prime} \mathrm{N}, 83^{\circ} 19.467^{\prime} \mathrm{W}$ ), and (3) the Fountain (FT, $45^{\circ}$ $3.747^{\prime} \mathrm{N}, 83^{\circ} 25.872^{\prime} \mathrm{W}$ ). Lower left inset: conceptual model of light intensity present within each sampling location. These differences exist due to differences in the amount of light that is filtered out by differing water column depths, ranging from $0 \%$ at FT and nearly $95 \%$ at MIS

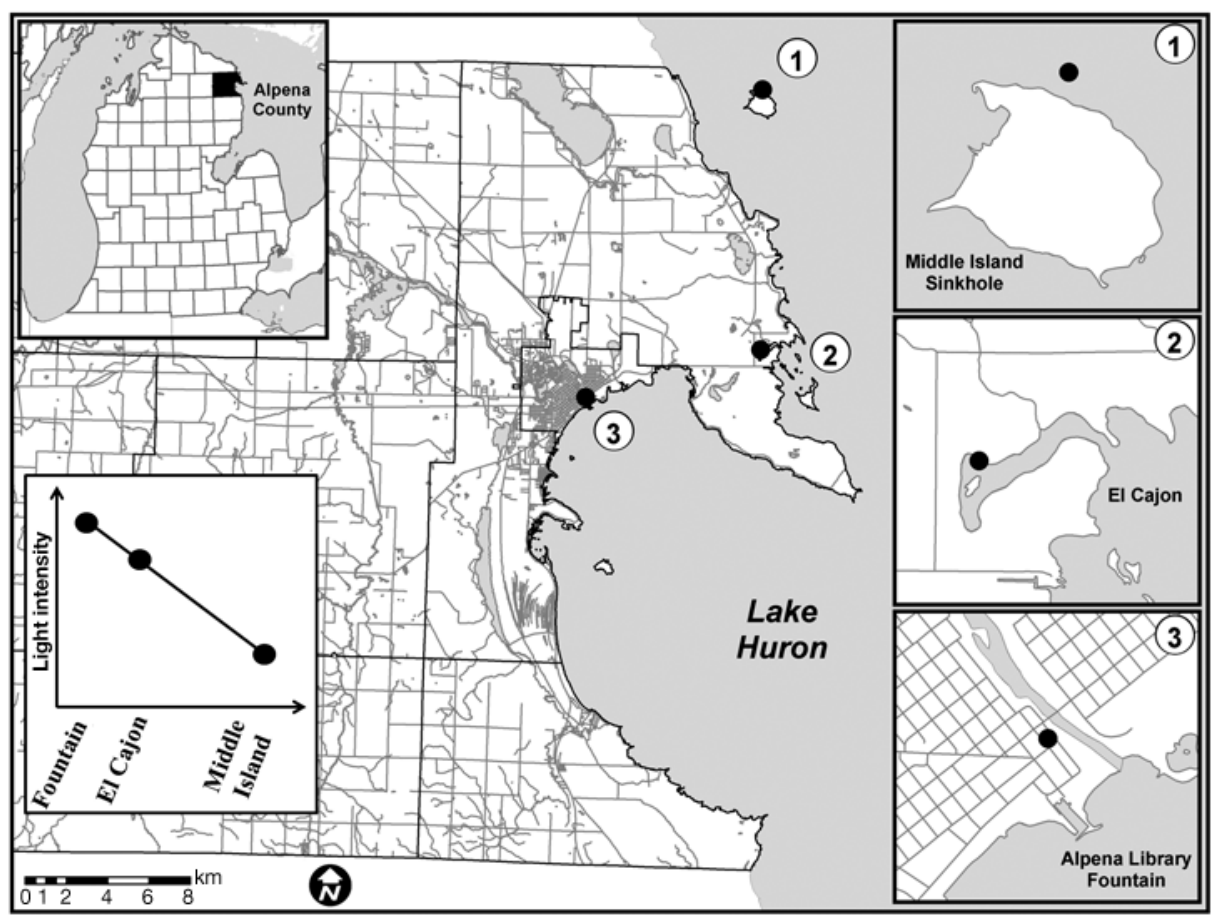

Middle Island Sinkhole

Middle Island Sinkhole (MIS) is a submerged, karst, bowl-shaped feature on the floor of Lake Huron $\left(45^{\circ} 11.927^{\prime} \mathrm{N}, 83^{\circ} 19.674^{\prime} \mathrm{W}\right.$; Fig. 1). This sinkhole ecosystem is $23 \mathrm{~m}$ deep, and receives roughly $\sim 10 \%$ of surface illumination. Two dominant cyanobacterial groups, most similar to Phormidium and Planktothrix make up the sprawling purple landscape, including raised finger structures created by microbial gasses produced within deep carbon-rich sediment (Voorhies et al. 2012, Nold et al. 2013). The surrounding lake bed is roughly $2 \mathrm{~m}$ deep on the south end (neighboring Middle Island) with an almost sheer drop down into the sinkhole, and opens up towards the northwest at about $23 \mathrm{~m}$ depth. A point-source vent discharges groundwater into a bowl located in what is known as the alcove, where, due to the groundwater's greater density, it collects and flows over the lip, spreading into the larger portion of the sinkhole. Many cracks in the lake bed act as small, non-point sources of groundwater. However, the single pointsource vent within the alcove is believed to be the main source of groundwater in the sinkhole. The venting groundwater remains well stratified due to thermo, pycno and chemoclines (Sanders et al. 2011).
Sampling

Samples were collected from each site for pigment extraction during daylight hours. FT samples were scraped from the large basin at the bottom of the fountain and hand-collected into freezer bag (Ziploc $\left.{ }^{\circledR}\right)$ bags. EC samples were pulled off of plants and debris and placed into freezer bag (Ziploc ${ }^{\circledR}$ ). SCUBA divers hand-collected prostrate mat samples at MIS using plastic coring tubes and rubber stoppers. Coring tubes were filled with approximately $15 \mathrm{~cm}$ of sediment along with the cyanobacterial mats laying on top of the sediment in each sample. All samples from each site were stored on ice immediately following collection and during transportation to the laboratory. MIS mat material was removed from the sediments prior to analysis, and pigment samples were stored at $-80^{\circ} \mathrm{C}$ until extraction (max. $3 \mathrm{mo}$ ).

Samples were collected periodically from all 3 sites from April 2012 to August 2013 (Fig. 2). Exceptions included limited growth at FT due to Alpena Library maintenance cleaning on one occasion (May 2012), and ice cover and rough weather conditions on Lake Huron and around Middle Island during the winter months. We contacted the library maintenance staff on subsequent sampling trips roughly $1 \mathrm{wk}$ prior to sampling to ensure that no cleaning would take place in the days leading up to sampling. 


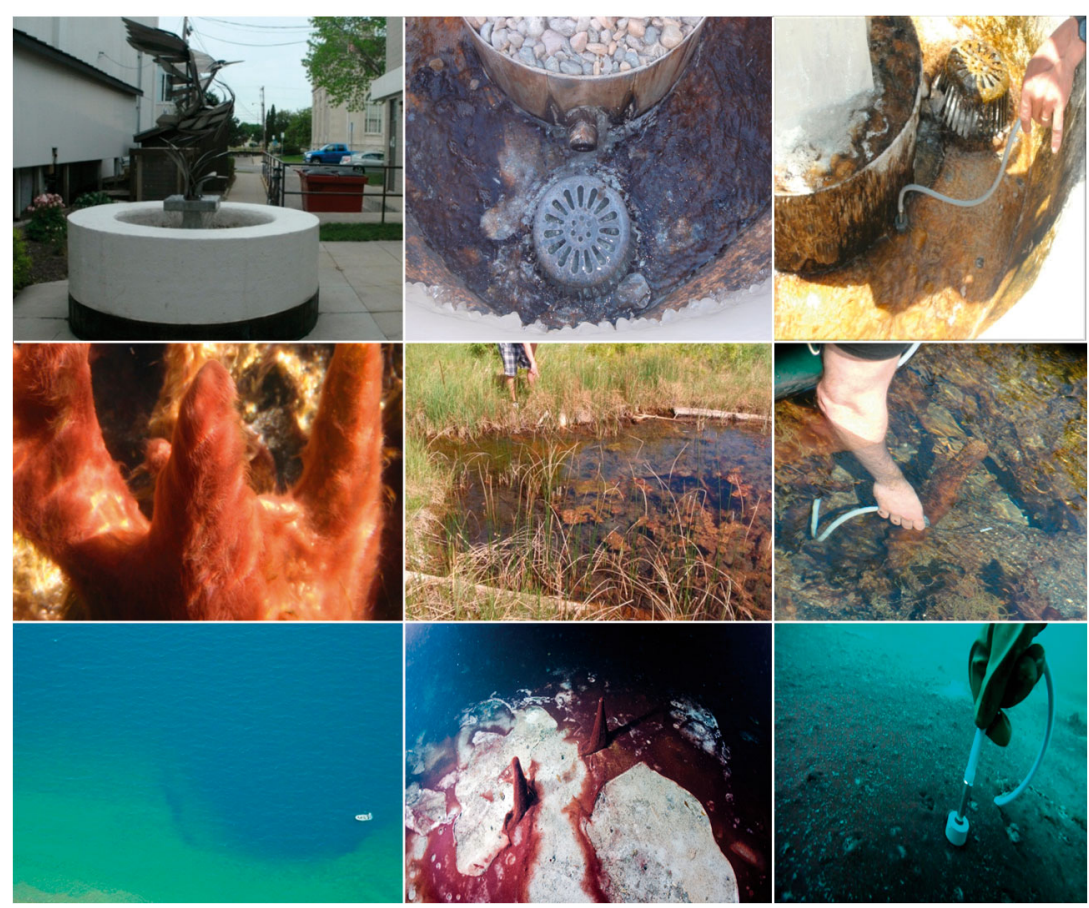

Fig. 2. Sinkhole study sites (see Fig. 1 for site locations). Top row: the Fountain $(\mathrm{FT})$; left: the fountain structure, a $183 \mathrm{~m}$ (600 foot) well that provides the groundwater for a community of cyanobacteria; middle: looking down into the FT where cyanobacterial mats grow; right: taking Diving-PAM measurements at FT. Middle row: El Cajon (EC); left: underwater close-up of cyanobacteria growing at EC; middle: EC has a centrally located vent that discharges groundwater; right: taking Diving-PAM measurements at EC. Bottom row: Middle Island Sinkhole (MIS); left: aerial view of MIS; middle: cyanobacteria growing at the bottom of MIS and 2 raised 'finger' structures; right: taking Diving-PAM measurements at MIS

\section{Field measurements}

Conductivity, dissolved oxygen (DO), $\mathrm{pH}$, and temperature were measured using a YSI 6600 multi-probe sonde (YSI). Photosynthetically active radiation (PAR) was measured just below the surface and at greatest depth at the site using a LiCor LI-192 underwater quantum sensor (LiCor Biotechnology). Deep PAR values were taken just above the mats to measure the level of PAR reaching the surface of the mats. YSI measurements were made at FT by dipping the sonde into a bucket with water collected from the fountain because the water was not deep enough for sonde measurements. At EC, YSI measurements were taken at the groundwater source and at various locations within the site to account for variation in shading due to detritus. Care was taken to ensure no shadows were cast onto the LiCor while taking measurements. These measurements were then averaged. At MIS, a YSI sonde was deployed in the center of the collection site during sampling and retrieved later. However, due to logistical constraints of operating at $\sim 23 \mathrm{~m}$ and over a large area, measurements could not always be repeated at precisely the same location, though care was taken to ensure relative proximity to the alcove and a reference marker grid that is in place. Full water column profiles were also obtained at MIS. A sonde was deployed at MIS and left to log data once daily throughout the winter (September 2012 to May 2013).

Functional variable fluorescence was measured at all sites at the time of collection (daylight hours, typically between 11:00 and 15:00 h) using a DivingPAM submersible fluorometer (Walz) before samples were collected. Measurements were taken in all areas of growth for all sites with the actinic light setting at 5 . These measurements represent $\left(F_{\mathrm{m}}{ }^{\prime}-\right.$ $\left.F^{\prime}\right) / F_{\mathrm{m}}{ }^{\prime}$, which is the ratio of maximal fluorescence range to the background minimum fluorescence level, or, in other words, the maximal PSII photochemical efficiency in actinic light. The fluorometer measures light energy that is re-emitted from chlorophyll $a(\operatorname{chl} a)$ that is not used for charge separation, heat dissipation or resonance (Cosgrove \& Borowitzka 2010, Ralph et al. 2010). Field measurements are said to be measured at 'steady state', meaning fluorescence was measured after cells had photoregulated to the ambient light, whereas laboratory experiments measured 'dark-adapted' fluorescence (Huot \& Babin 2010).

Phycobilin extractions (phycoerythrin and phycocyanin) were analyzed using a spectrophotometer according to Lawrenz et al. (2011). Extractions were performed on ice by two $30 \mathrm{~s}$ sonication pulses followed by a $24 \mathrm{~h}$ extraction at $5^{\circ} \mathrm{C}$ in $0.1 \mathrm{M}$ phosphate buffer (pH 6.0). These samples were then centrifuged at $42400 \times g$ for $20 \mathrm{~min}$ and the supernatant was ana- 
lyzed in a spectrophotometer. Phycoerythrin was measured at $545 \mathrm{~nm}$ and phycocyanin at $620 \mathrm{~nm}$, and both were scatter-corrected by subtracting the absorbance of each sample at $750 \mathrm{~nm}$. Chlorophyll extractions were performed by sonication and extraction with dimethylformamide. Phaeopigment correction and final chlorophyll calculations were conducted according to equations derived by Lorenzen (1967). Samples were measured for absorbance at $665 \mathrm{~nm}$, acidified and re-measured to correct for phaeopigments. All pigment determinations were standardized to dry weight after completely drying samples in a desiccator.

PAR measurements were only taken on the days of sampling. In order to assess the effect of year-long PAR (not measured), long-term PAR data were retrieved from http://ameriflux.ornl.gov/ (courtesy of Oak Ridge National Laboratory). Data used were from the University of Michigan Biological Station (UMBS) because this weather station site was the closest station that measured PAR over the sampling period.

\section{Inhibitor experiment}

Field samples were pooled ( 10 g dry weight) into $1 \mathrm{l}$ of groundwater and gently agitated by a stir bar (MIS samples were removed from the underlying sediment) to make homogeneous slurry stocks of the filaments in sinkhole-derived groundwater for each site. After samples were distributed to the vials, the cyanobacterial filaments reaggregated to form something resembling a mat. This process occurred for all samples from all sites within 1 or $2 \mathrm{~h}$. Stocks were prepared within 24 to $48 \mathrm{~h}$ of collection. All samples were prepared and grown in groundwater from the FT site (which has a relatively similar water chemistry to the other sites) due to ease of collection and a significant absence of any other large particulate organic matter compared to the other sites (this water was not filtered, so some particulates or microbes may have been present). Care was taken to exclude any extraneous particulate organic matter and invertebrates while preparing stock cultures. Cell suspensions were then distributed into $22 \mathrm{ml}$ scintillation vials and placed in a Fisher Scientific low-temperature incubator at $9.5^{\circ} \mathrm{C}$ with an internal, independent thermometer check.

Samples from all sites were distributed into vials and left open to incubator air (fully oxygenated) and placed under full light. Two PSII inhibitors, $\mathrm{Na}_{2} \mathrm{~S} 7 \mathrm{H}_{2} \mathrm{O}\left(\mathrm{H}_{2} \mathrm{~S}_{;} 25\right.$ to $\left.50 \mu \mathrm{M}\right)$ and 3-(3,4-dichloro- phenyl)-1,1-dimethylurea (DCMU; $10 \mu \mathrm{M}$ ) were added to cultures daily. The $\mathrm{H}_{2} \mathrm{~S}$ was used to mimic in vivo sulfide, while DCMU was used as an alternate inhibitor to ensure that samples were susceptible to PSII inhibition. Cultures were allowed a full $24 \mathrm{~h}$ acclimation period, then an initial measurement was made. Immediately after this initial measurement, inhibitor additions were administered into the vials and cultures were allowed to sit for $24 \mathrm{~h}$ before the next time point. The next measurement was made, followed by administration of inhibitor treatments. This pattern continued for $5 \mathrm{~d}$. Chemical inhibitors were always added after sampling such that samples were exposed to the chemical for $24 \mathrm{~h}$ before sampling. Upon re-addition of photosynthetic inhibitors, half of the media was removed and fresh groundwater added, and additional inhibitor added to bring the concentration back to the desired level. Buffers were not used in the groundwater media, so reported inhibitor concentrations are estimated based on a $\mathrm{pH}$ of 7 to 8 .

Following this study, the same cultures were continued for several days, only replenishing the groundwater media but with no addition of photosynthetic inhibitors. Inhibitor treatments then continued with the same pattern as above using new, higher concentrations of both sulfide (62.5 to $125 \mu \mathrm{M}$ ) and DCMU $(25 \mu \mathrm{M})$, and then yet another higher concentration of both sulfide $(125$ to $250 \mu \mathrm{M})$ and DCMU $(50 \mu \mathrm{M})$, and finally a lower treatment of sulfide $(62.5$ to $125 \mu \mathrm{M})$ and DCMU $(25 \mu \mathrm{M})$. Yield measurements were made using the Diving-PAM by placing the fiber optic cable into the scintillation vial and measuring from a set distance just above the mat $(<5 \mathrm{~mm})$, taking care that the probe was not moved during measurement. PAM measurements were taken in a dimly lit room $\left(\sim 50 \mu \mathrm{mol}\right.$ photons $\left.\mathrm{s}^{-1} \mathrm{~m}^{-2}\right)$ with indirect light. Pigment samples were obtained by carefully removing a small piece of the mat, and were analyzed for chlorophyll, phycoerythrin, and phycocyanin. Note that some time points are missing for pigment analyses. This was to conserve sample volumes throughout the duration of the experiment.

\section{Alternate pigment extraction and analysis}

A separate analysis of cyanobacterial mat chlorophyll and phycobiliproteins (phycocyanin, PC and phycoethrin, PE) was conducted under experimentally variable light conditions using an alternate pigment extraction analysis method with mat samples collected from MIS during the fall of 2015. Replicates 
of mat samples were made into a slurry and placed under 3 different light conditions: light, total darkness, and control (kept at $10^{\circ} \mathrm{C}$ with a neutral density filter and $12 \mathrm{~h}$ light:dark cycle). The methods for pigment extraction were adapted from Montechiaro \& Giordano (2006) using a Shimadzu UV-1601 UV/Vis visible spectrophotometer. Pigment concentrations were determined according to Porra et al. (1989) and Bennett \& Bogorad (1973), and replicates and their means were compared using ANOVA.

\section{Genetic analyses}

DNA was extracted using the FastDNA soil spin kit (MP Biomedical), following the manufacturer's protocol with modification of $0.3 \mathrm{~g}$ of beads in the beadbeating step. A Picogreen assay (Invitrogen) was used to quantify total genomic DNA. The V4 region of the 16S rRNA gene of Bacteria and Archaea was amplified with fusion primers containing dual index barcodes and Illumina-specific adaptors (Kozich et al. 2013). Reactions consisted of $10 \mu \mathrm{l}$ of HotMasterMix (5Primer), $400 \mathrm{pM}$ each of forward and reverse primer, $1 \mu \mathrm{l}$ of DNA, and water to a total volume of $25 \mu \mathrm{l}$. Reactions were conducted in triplicate for each sample in the following thermocycling conditions: initial denaturation at $94^{\circ} \mathrm{C}$ for $4 \mathrm{~min} ; 30$ cycles of $94^{\circ} \mathrm{C}$ for $30 \mathrm{~s}, 50^{\circ} \mathrm{C}$ for $45 \mathrm{~s}, 72^{\circ} \mathrm{C}$ for $1 \mathrm{~min}$; and a final extension at $72^{\circ} \mathrm{C}$ for $10 \mathrm{~min}$. Triplicate reactions were pooled and cleaned using the UltraClean PCR cleanup kit (MoBio), then quantified with a Picogreen assay. Samples were combined in equimolar concentration and submitted to the University of Michigan Microbial Systems Sequencing Core facility for Illumina MiSeq sequencing using the $2 \times 250$ cycle V2 chemistry.

Paired-end reads were quality controlled using Python scripts (https://github.com/meren/illuminautils), and were retained if they overlapped over $200 \mathrm{bp}$ with a maximum of 5 mismatches of quality 25 or higher. Reads were clustered into ribotypes using Minimum Entropy Decomposition (Eren et al. 2015) with the following parameters: discriminants $=4$, relocate outliers, minimum entropy $=0.0965$, minimum substantive abundance of a node $=5$, maximum variation allowed in a node $=3$. These ribotypes typically represent clusters containing highly related sequences that share $>97 \%$ and often $>99 \%$ sequence identity. Representative sequences from each ribotype were queried using GAST (Huse et al. 2008) against a curated SILVA108 database. Ribotypes of unknown or eukaryotic taxonomy were discarded. Sequences were checked for chimeras against the SILVA Gold database (Schloss et al. 2009) using the UCHIME chimera checker (Ehling-Schulz \& Scherer 1999). Reads were queried using BLAST against a previously published metagenomic dataset from MIS (Voorhies et al. 2012) to check for similarity to previously analyzed sequences.

\section{Statistical analyses}

PAR and field measurements (yield, chlorophyll, phycoerythrin, and phycocyanin) were divided into summer and winter seasons (May to September and October to April, respectively). Field measurements were compared between sites with ANOVA. Significant findings were followed by a post hoc Tukey test. Correlation analyses were conducted between all measured field parameters (chlorophyll, phycoerythrin, phycocyanin, phycoerythrin:phycocyanin, phycobilins:chlorophyll, $F_{\mathrm{v}}{ }^{\prime} / F_{\mathrm{m}}{ }^{\prime}$, and PAR). Regressions were conducted between $F_{\mathrm{v}}{ }^{\prime} / F_{\mathrm{m}}{ }^{\prime}$ and the different sources of PAR data (surface PAR, bottom PAR, and weather station PAR) to show any differences in using these different sources of data. Kruskal-Wallis tests were also used for inhibitor studies to compare the 2 treatments and control group.

Ribotypes were analyzed using the $\mathrm{R}$ statistical platform (R Core Team 2012) and the packages 'vegan' (Oksanen et al. 2013), 'ggplot2' (Wickham 2009), 'reshape' (Wickham 2007), 'gtools' (Warnes et al. 2015), 'gridExtra' (Auguie 2015), 'plyr' (Wickham 2011), 'rje' (Evans 2014) and 'ggdendro' (de Vries \& Ripley 2014). For alpha diversity indices, samples were rarefied to 13958 sequences. For figures, experimental samples were pooled for each site (FT, EC, and MIS); the 3 pools were rarefied to 127278 sequences, and relative abundances were analyzed.

\section{RESULTS}

Physical parameters of the groundwater from each sample location are compared in Table 1. Despite being geographically separated, the measured parameters are quite similar, consistent with a common source of groundwater. Three parameters were measured over the winter period at MIS (Table 2) to show physical parameters in the months in which sampling was not logistically feasible. PAR data for each site are shown in Table 3, highlighting the main differences in light climate for each site. Compar- 
Table 1. Year-long average ( $\pm 1 \mathrm{SE}$ ) of physical parameters of water at the 3 study sites: the Fountain (FT), El Cajon (EC), and Middle Island Sinkhole (MIS). MIS column represents data taken from the groundwater layer. These parameters are not strongly influenced by the surrounding area or by seasonality. DO: dissolved oxygen; Cond: conductivity

\begin{tabular}{|lccc|}
\hline & FT & EC & MIS \\
\hline DO $\left(\mathrm{mg} \mathrm{l}^{-1}\right)$ & $3.68 \pm 2.54$ & $1.02 \pm 0.98$ & $0.89 \pm 0.51$ \\
Temp $\left({ }^{\circ} \mathrm{C}\right)$ & $11.46 \pm 0.95$ & $10.28 \pm 0.11$ & $9.42 \pm 1.22$ \\
Cond $\left(\mu \mathrm{cm}^{-1}\right)$ & $2491 \pm 22.26$ & $2431 \pm 68.12$ & $1816 \pm 52.65$ \\
$\mathrm{pH}$ & $7.27 \pm 0.26$ & $7.12 \pm 0.42$ & $7.29 \pm 0.29$ \\
\hline
\end{tabular}

Table 2. Data from winter months at Middle Island Sinkhole (MIS) when sampling was not possible. Data was logged by a YSI deployed in the alcove. DO: dissolved oxygen

\begin{tabular}{|lc|}
\hline Parameter & MIS alcove \\
\hline Temperature $\left({ }^{\circ} \mathrm{C}\right)$ & 9.2 \\
Conductivity $\left(\mathrm{S} \mathrm{cm}^{-1}\right)$ & 2178 \\
DO $\left(\mathrm{mg} \mathrm{l}^{-1}\right)$ & 0.95 \\
\hline
\end{tabular}

isons can be made between the summer (May through September) and winter (October through April) in order to see the full effect of seasonality. Separating the data in this manner was important due to the lack of winter data for MIS. The summer had higher PAR values for both sites where full-year sampling was possible. MIS had the highest degree of PAR filtering through the water column, followed by EC, and then FT where there is virtually no water column. The degree to which PAR was filtered at EC was relatively unchanged between the summer and winter. Year-long $F_{\mathrm{v}}{ }^{\prime} / F_{\mathrm{m}}{ }^{\prime}$ measurements are presented in Fig. 3, showing chlorophyll, phycocyanin, phycoerythrin, and yield. Care should be taken in interpreting these results, as the data for MIS is incomplete due to logistics and therefore is not truly 'year-long' data like the others. Average values of summer and winter seasons of biological parameters are presented in Table 4. This was organized into summer and winter as well to assess the impact of seasonality. Results of an ANOVA tests showed that chlorophyll levels differed between sites (EC and MIS in one group, FT in the other and having a significantly lower value), while all other averaged year-long parameters were not significantly different. No differences were detected in the winter season between FT and EC. The seasonal trend of photosynthetic yield compared to PAR is displayed in Fig. 4.
Table 3. Average year-long light measurements (umol photons $\mathrm{s}^{-1} \mathrm{~m}^{-2}$ ) by season at each study site (FT: the Fountain; EC: El Cajon; MIS: Middle Island Sinkhole) comparing surface photosynthetically active radiation (PAR), PAR reaching the cyanobacterial mat ('Bottom PAR as \% of surface'; note that this is the light climate that the mats experience. PAR measurements were taken at the time of sampling for several minutes, typically at midday. These data are given in italics to highlight this aspect), and the percent of surface PAR that reaches the cyanobacterial mat

\begin{tabular}{|lccc|}
\hline Parameter & FT & EC & MIS \\
\hline Winter (Nov to Mar) & & & \\
Surface PAR & 985 & 1575 & - \\
Bottom PAR & 985 & 873 & - \\
Bottom PAR as \% of surface & 100 & 55 & - \\
Summer (Apr to Oct) & & & \\
Surface PAR & 2356 & 2307 & 2218 \\
Bottom PAR & 2356 & 1360 & 94 \\
Bottom PAR as \% of surface & 100 & 59 & 4 \\
Year-long & & & \\
Surface PAR & 1879 & 1824 & 2218 \\
Bottom PAR & 1879 & 1008 & 94 \\
Bottom PAR as \% of surface & 100 & 54 & 4 \\
\hline
\end{tabular}

The results of correlation analyses of biological parameters and the resulting $p$-values are presented in Table 5. Chlorophyll content was significant when compared to PAR for EC and MIS (not FT), while all sites had significant comparisons between chlorophyll and $F_{\mathrm{v}}{ }^{\prime} / F_{\mathrm{m}}{ }^{\prime}$. Interestingly, FT had a significantly different chlorophyll value. PAR and $F_{\mathrm{v}}{ }^{\prime} / F_{\mathrm{m}}{ }^{\prime}$ results were significant for $\mathrm{EC}$ and quite close to significance at FT ( $p<0.001$ and 0.0552 , respectively). PAR is likely an important driving factor, so several sources of PAR measurements were analyzed as well (Table 6), though these analyses yielded no change in significant test results.

Inhibitor studies demonstrated a substantial effect of DCMU, but not $\mathrm{H}_{2} \mathrm{~S}$, on $F_{\mathrm{v}}{ }^{\prime} / F_{\mathrm{m}}$ ' for all sites and concentrations used (Fig. 5, Table 7, see Figs. S1S3 in the Supplement at www.int-res.com/articles/ suppl/a079p063_supp.pdf). No significant effects of inhibitor treatments on chlorophyll, phycoerythrin or phycocyanin were detected. Time series of inhibitor experiments showed fluctuations that appeared to be significant, but they were minimal, and timeintegrated averages showed that these differences are likely not significant. No time-integrated values were available for the use of increased inhibitor concentration as many cultures died as a result of prolonged addition of DCMU. Despite a 5-fold increase in the concentration of both inhibitors, the trend of decreased yield for DCMU and no effect on $\mathrm{H}_{2} \mathrm{~S}$ continued (Fig. 6). 

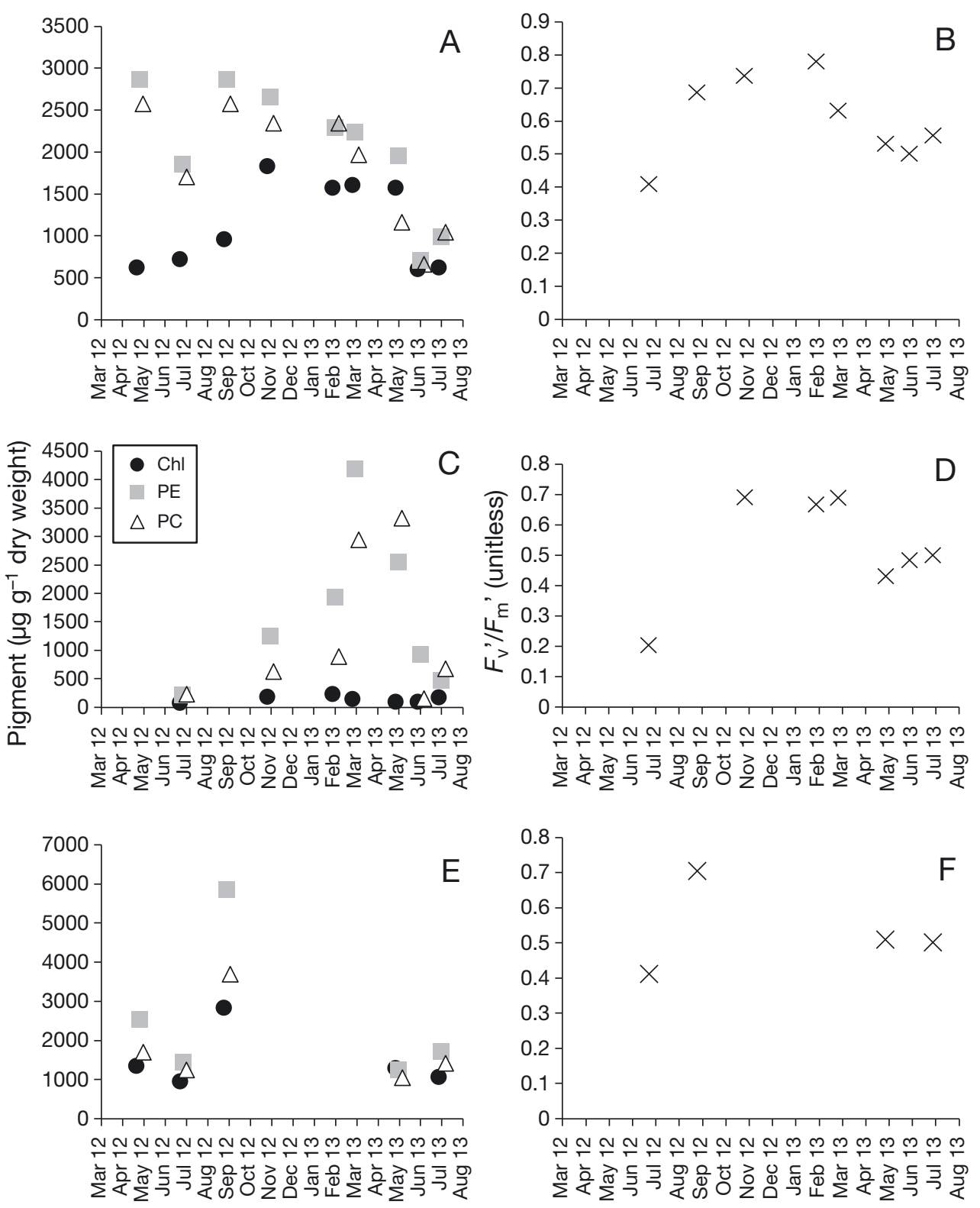

Fig. 3. Year-long pigment and photosynthetic yield data for all 3 study sites: $(A, B)$ the Fountain; (C,D) El Cajon; $(\mathrm{E}, \mathrm{F})$ Middle Island Sinkhole. $(\mathrm{A}, \mathrm{C}, \mathrm{E})$ show pigment data (Chl: chlorophyll; PE: phycoerythrin; PC: phycocyanin). $(\mathrm{B}, \mathrm{D}, \mathrm{F})$ shows photosynthetic yield $\left(F_{\mathrm{v}}{ }^{\prime} / F_{\mathrm{m}}{ }^{\prime}\right)$. Data points are slightly offset due to overlapping points. Note that the scale for pigment concentration is different for each site, while yield is constant

Cyanobacteria dominated the bacterial communities from all 3 sites, with their abundance being at least double that of the next most abundant group (Fig. 7, Table S1 in the Supplement). Finer analysis of groups within Cyanobacteria revealed that one cyanobacterial ribotype, closely related to Phormidium autumnale, represented over $80 \%$ of cyanobacterial sequences at all 3 sites (Fig. 7, Table S2). Other cyanobacterial ribotypes were present at low abundance. Ribotypes attributed to Planktothrix were well represented in the FT and MIS communities, and rare or not observed in EC samples. EC had one unclassified cyanobacterial ribotype that accounted for $10.5 \%$ of cyanobacterial sequences, which was not detected at the other 2 sites. The sequences of the dominant Phormidium and Planktothrix ribotypes were $100 \%$ identical to the dominant genotypes of these populations identified in previous metagenomic studies of MIS (Voorhies et al. 2012, 2016).

In the fall 2015 samples, phycobiliproteins had consistently higher concentrations than chlorophyll, and PE was found in higher concentrations than PCquite similar to earlier observations (Fig. S4 in the Supplement). The control conditions had the highest amount of pigments, followed by the dark conditions, followed by the light conditions. Concentrations of chlorophyll, PC, and PE between control, light and dark conditions all differed significantly ( $p<0.001)$. 
Table 4. Average biological parameters for each site (FT: the Fountain; EC: El Cajon; MIS: Middle Island Sinkhole) from 2012 to 2013 (units: yield, unitless; pigments [chl, phycoerythrin, phycocyanin]: $\mu g^{-1}$ dry weight). Right-hand column shows the p-value for the ANOVA test for the parameter in that column between sites, with significant values in bold $(\alpha=0.05)$, and the site(s) average value that was statistically different from the others via post hoc Tukey HSD test indicated by $\left({ }^{*}\right)$

\begin{tabular}{|lcccc|}
\hline Site & FT & EC & MI & p-value \\
\hline Winter (Nov to Mar) & & & & \\
Yield & 0.68 & 0.72 & - & 0.504 \\
Chl & 188 & 1668 & - & $<\mathbf{0 . 0 0 0 1}$ \\
Phycoerythrin & 2455 & 2396 & - & 0.928 \\
Phycocyanin & 1489 & 2217 & - & 0.215 \\
Summer (Apr to Oct) & & & & \\
Yield & 0.37 & 0.53 & 0.58 & 0.27 \\
Chl & $110^{*}$ & 849 & 1532 & $\mathbf{0 . 0 0 3 6}$ \\
Phycoerythrin & 1038 & 1871 & 1893 & 0.233 \\
Phycocyanin & 1098 & 1619 & 813 & 0.59 \\
Year-long & & & & \\
Yield & 0.52 & 0.6 & 0.53 & 0.606 \\
Chl & $143^{*}$ & 1122 & 1532 & $<\mathbf{0 . 0 0 0 1}$ \\
Phycoerythrin & 1645 & 2046 & 1893 & 0.426 \\
Phycocyanin & 1265 & 1818 & 813 & 0.375 \\
\hline
\end{tabular}

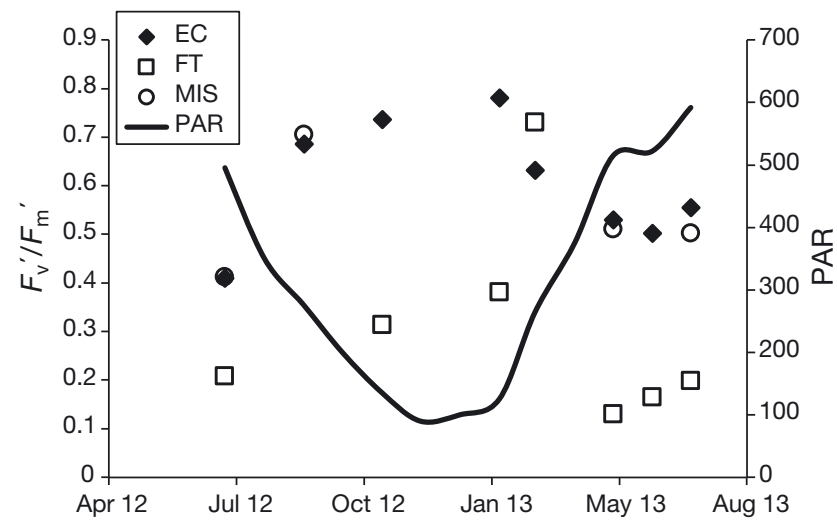

Fig. 4. Seasonal trend in photosynthetic yield for all 3 study sites (EC: El Cajon; FT: the Fountain; MIS: Middle Island Sinkhole). $F_{\mathrm{v}}{ }^{\prime} / F_{\mathrm{m}}$ ' shows an inverse relationship with photosynthetically active radiation (PAR) (PAR data source: Oak Ridge National Laboratory, Ameriflux, site: University of Michigan Biological Station, UMBS)

\section{DISCUSSION}

\section{PAR is an important driver in mat ecosystems}

PAR is a key driver of photosynthetic efficiency in the mat ecosystems studied here, as indicated by our analysis of cyanobacteria across temporal and spatial gradients of light. The high variability of PAR at FT is likely due to the site being located between 2 build-
Table 5. p-values of correlation analyses between various parameters at all sites (FT: the Fountain; EC: El Cajon; MIS: Middle Island Sinkhole) for the whole sampling period (2012 and 2013; $\mathrm{n}=21,30$, and 17 for FT, EC and MIS, respectively). Statistically significant values are in bold $(\alpha=0.05)$. Chl: chlorophyll; PE: phycoerythrin; PC: phycocyanin; Phy: phycobilins. Missing values are due to redundant values and tests between identical parameters (i.e. chl and chl)

\begin{tabular}{|lccc|}
\hline & PAR & Yield & Chl \\
\hline FT & & & \\
Chl & 0.0741 & $\mathbf{0 . 0 3 9 9}$ & \\
PE & 0.3640 & 0.1905 & 0.7083 \\
PC & 0.9252 & 0.6257 & 0.8799 \\
PE:PC & 0.9823 & 0.6869 & 0.8209 \\
Phy:Chl & 0.0926 & 0.1867 & \\
Yield & 0.0552 & & \\
EC & & & \\
Chl & $\mathbf{0 . 0 1 6 4}$ & $\mathbf{0 . 0 5 4 3}$ & \\
PE & 0.1445 & 0.0569 & 0.2509 \\
PC & 0.0896 & $\mathbf{0 . 0 2 7 7}$ & 0.4149 \\
PE:PC & 0.5580 & 0.7564 & 0.4445 \\
Phy:Chl & 0.2791 & 0.6401 & \\
Yield & $\mathbf{0 . 0 0 0 9}$ & & \\
MIS & & & \\
Chl & $\mathbf{0 . 0 3 2 3}$ & $\mathbf{0 . 0 3 1 5}$ & \\
PE & $\mathbf{0 . 0 1 2 8}$ & 0.0706 & $\mathbf{0 . 0 0 4 4}$ \\
PC & $\mathbf{0 . 0 1 3 1}$ & 0.0695 & $\mathbf{0 . 0 0 4 1}$ \\
PE:PC & 0.8628 & 0.5054 & 0.7418 \\
Phy:Chl & $\mathbf{0 . 0 0 5 3}$ & 0.2004 & \\
Yield & 0.1762 & & \\
& & & \\
\hline
\end{tabular}

Table 6. p-value results from linear regression analysis $(\alpha=$ 0.05 , significant values in bold) between $F_{\mathrm{v}}{ }^{\prime} / F_{\mathrm{m}}{ }^{\prime}$ and different data sources for photosynthetically active radiation (PAR) measurements collected at the 3 study sites (FT: the Fountain; EC: El Cajon; MIS: Middle Island Sinkhole). Surface PAR and Bottom PAR data values were collected on-site with the LiCor meter; 'weather station' data was obtained from the Ameriflux database (University of Michigan Biological Station, UMBS)

\begin{tabular}{|lccc|}
\hline & FT & EC & MIS \\
\hline Surface PAR & 0.1109 & $\mathbf{0 . 0 2 4 3}$ & 0.8720 \\
Bottom PAR & 0.1109 & $\mathbf{0 . 0 1 6 8}$ & 0.9772 \\
Weather Station & 0.0552 & $\mathbf{0 . 0 0 0 1}$ & 0.1762 \\
\hline
\end{tabular}

ings as well as a second story skyway connecting the 2 buildings causing the structure to have periods of either direct sunlight or shade. The high year-long PAR at this site was paired with the lowest year-long $F_{\mathrm{v}}{ }^{\prime} / F_{\mathrm{m}}{ }^{\prime}$ and a significantly lower level of chlorophyll. These are likely responses to high PAR to regulate photosynthesis. Increased pigmentation during high PAR can lead to oxidative damage, so the communities downregulate pigments to prevent this. The 

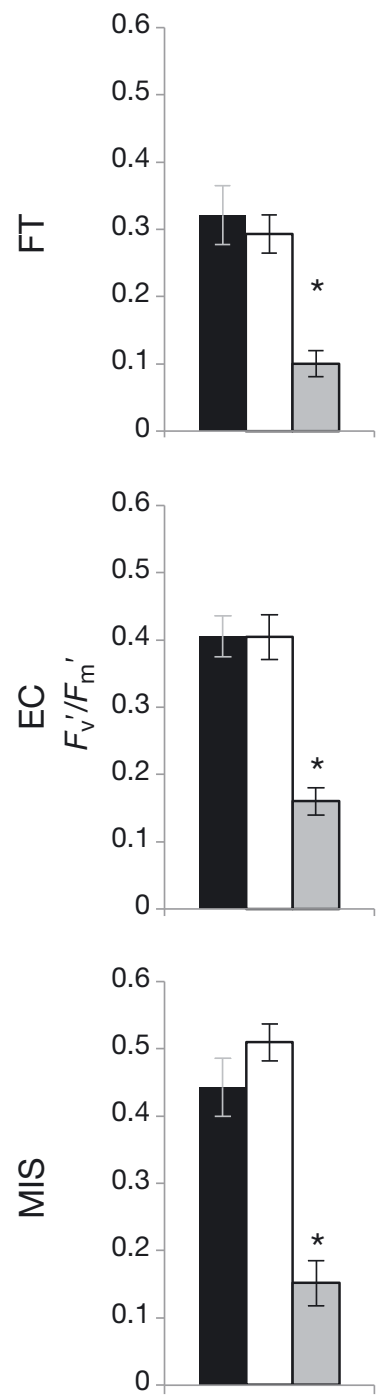
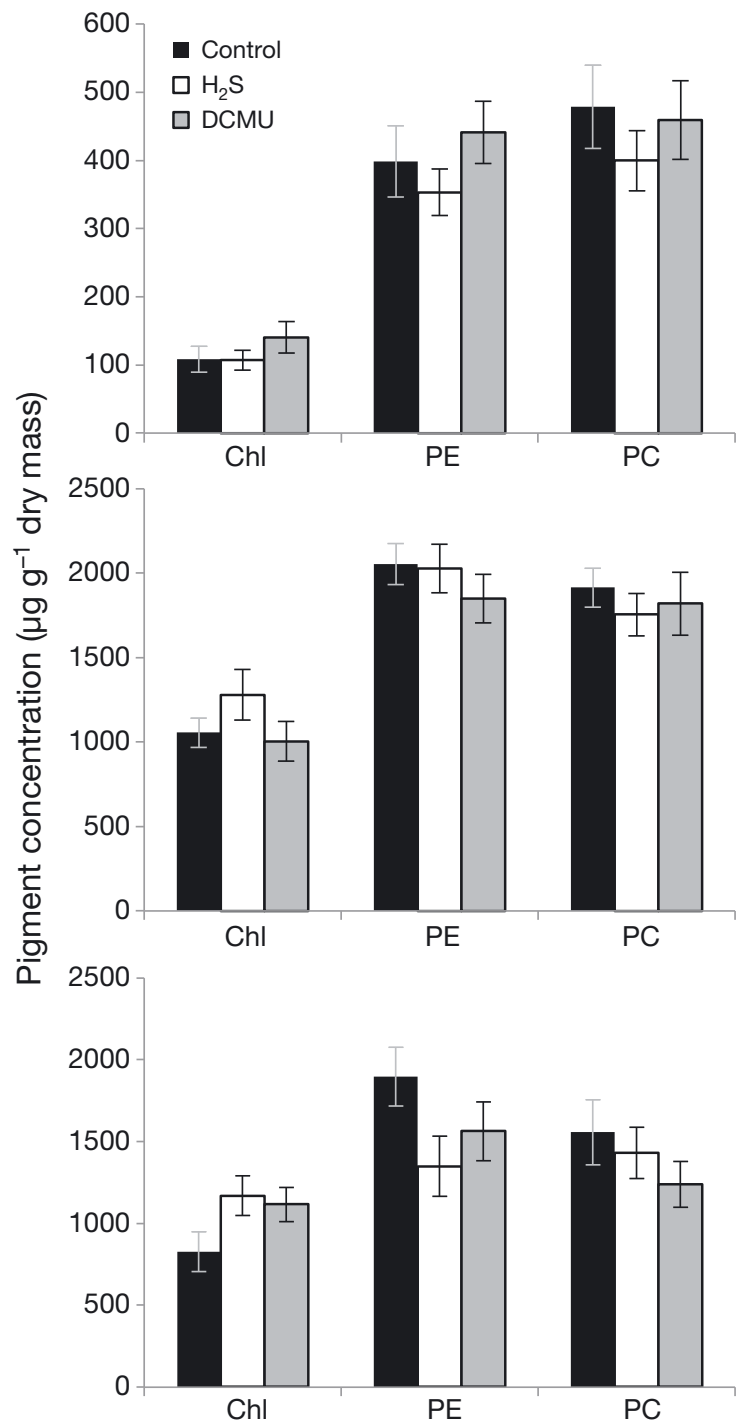

Fig. 5. Measured $F_{\mathrm{v}}{ }^{\prime} / F_{\mathrm{m}}{ }^{\prime}$, chlorophyll $(\mathrm{Chl})$, phycoerythrin (PE), and phycocyanin (PC) from addition of $\mathrm{H}_{2} \mathrm{~S}(25$ to $50 \mu \mathrm{M})$, DCMU $(10 \mu \mathrm{M})$, and a control on samples from El Cajon (EC), the Fountain (FT), and Middle Island Sinkhole (MIS). 'Control' refers to 'time 0,' or the start of the experiment. Bars: average of all measurements taken through the duration of the experiment; error bars: SE. * signifies a statistically significant group

lower $F_{\mathrm{v}}{ }^{\prime} / F_{\mathrm{m}}$ ' observed may be due to oxidative damage and increased detritus on the mats.

Chlorophyll differed significantly despite EC and FT receiving similar PAR levels in the winter. This may be due to the 'spikes' of PAR that occur at FT, when the location experiences direct sunlight. EC mats may not receive as much PAR as indicated due to microhabitat structure. The $F_{\mathrm{v}}{ }^{\prime} / F_{\mathrm{m}}{ }^{\prime}$ and chlorophyll measured at EC and MIS were both significantly higher than FT, likely because the level of PAR was much lower than at FT. Chlorophyll down-regulation would not be necessary in more moderate PAR con- ditions, especially at MIS where PAR was consistently low. Relatively stable conditions may select for high and steady levels of pigmentation in MIS microbial mats.

\section{Seasonality of biological parameters}

$F_{\mathrm{v}}{ }^{\prime} / F_{\mathrm{m}}{ }^{\prime}$ data revealed an apparent seasonal trend where recorded values were consistently higher during the colder, low-light months and lower during the warmer, high-light months (Fig. 4). Similar findings have been reported in other studies (Warner et al. 2002, Abdala-Díaz et al. 2006, Hawes et al. 2014). Warner et al. (2002) found this trend in coral-associated diatoms at varying depths, where more shallow measurements were more highly variable, likely due to higher variation in PAR. Increased variability in shallow sites was not found in the present study, although this may be misleading due to differences in sites, (discussed below; Table 3). Additionally, Warner et al. (2002) reported higher average $F_{\mathrm{v}}{ }^{\prime} / F_{\mathrm{m}}{ }^{\prime}$ values at greater depth, whereas we found no trend with depth; indeed, photosynthetic yield was indistinguishable among sites over the course of the year, within the summer, and within the winter (Table 4). Abdala-Díaz et al. (2006) found similar seasonal trends in a brown algae, as well as diel patterns where $F_{\mathrm{v}}{ }^{\prime} / F_{\mathrm{m}}{ }^{\prime}$ was higher during low-light periods of the day (morning and evening; a similar trend, but on a much shorter time scale) and reached a minimum at mid-day. Hawes et al. (2014) found an inverse relationship between PAR and $F_{\mathrm{v}}{ }^{\prime} / F_{\mathrm{m}}{ }^{\prime}$ fluorescence in a similar microbial mat community that resides under ice-covered lakes in Antarctica. While we were unable to make repeated measurements at the sites over the course of a day, the year-long inverse relationship between PAR and yield remained, and thus it seems likely that a similar diel trend exists at our 3 study sites.

Similarly, pigments appeared to vary seasonally. In general, pigment levels tended to peak during the winter months, with distinct differences in baseline 
Table 7. Statistical analyses of inhibitor studies grouped by site (FT: the Fountain; EC: El Cajon; MIS: Middle Island Sinkhole). Within each group, top 3 values show ShapiroWilk test $p$-value results; significant results are in bold and indicate non-normal sample distribution. Kruskal-Wallis test $p$-value results are for inhibitor additions $(\alpha=0.05)$. Significant values are in bold, and indicate an effect of either $\mathrm{H}_{2} \mathrm{~S}$ and/or DCMU (the distinction between which treatment caused a positive test result is indicated by ${ }^{*}$ in Fig. 5)

\begin{tabular}{|lcccc|}
\hline Treatment & $F_{\mathrm{v}}{ }^{\prime} / F_{\mathrm{m}}{ }^{\prime}$ & $\mathrm{Chl}$ & $\mathrm{PE}$ & $\mathrm{PC}$ \\
\hline FT & & & & \\
Control & 0.4389 & 0.7164 & 0.1162 & 0.3285 \\
DCMU & $\mathbf{0 . 0 0 0 3}$ & 0.909 & 0.9963 & 0.2183 \\
$\mathrm{H}_{2} \mathrm{~S}$ & 0.383 & 0.954 & 0.7173 & 0.3358 \\
Kruskal-Wallis test & $\mathbf{0 . 0 0 2}$ & 0.4691 & 0.2651 & 0.7173 \\
EC & & & & \\
Control & 0.3866 & 0.635 & 0.4121 & 0.9442 \\
DCMU & $\mathbf{0 . 0 0 4 2}$ & 0.1664 & 0.1162 & 0.7158 \\
H2S & 0.4815 & 0.6879 & 0.1162 & 0.0586 \\
Kruskal-Wallis test & $<\mathbf{0 . 0 0 1}$ & 0.2509 & 0.4944 & 0.9047 \\
MIS & & & & \\
Control & 0.0825 & 0.1572 & 0.8795 & 0.2074 \\
DCMU & $\mathbf{0 . 0 2 2 3}$ & 0.1393 & 0.05 & 0.7899 \\
H 2 S & 0.0707 & 0.6381 & 0.4446 & 0.7951 \\
Kruskal-Wallis test & $<\mathbf{0 . 0 0 1}$ & $\mathbf{0 . 0 2 2 2}$ & 0.1014 & 0.4275 \\
\hline
\end{tabular}

pigment levels. For example, EC tended to have a higher level of chlorophyll year-round than FT. Chlorophyll was higher in the winter months, likely as a result of lower PAR, meaning chlorophyll followed a relatively inverse relationship with PAR. Chlorophyll was lowest at FT due to high and variable sunlight, while chlorophyll was highest at MIS due to low and relatively stable PAR. Similar observations were made in 2015 as well. Phycoerythrin and phycocyanin did not exhibit as clear a seasonal pattern, especially at EC where phycobilins were highest around summer of 2012 but lowest in July 2013 (no significant difference). It is unclear why this would be, as no drastic changes in PAR, temperature, or other parameters occurred between 2012 and 2013.

$F_{\mathrm{v}}{ }^{\prime} / F_{\mathrm{m}}{ }^{\prime}$ is affected by PAR, but in order to maintain homeostasis, cells must keep $F_{\mathrm{v}}{ }^{\prime} / F_{\mathrm{m}}{ }^{\prime}$ within some optimal range. Staying within this range must be accomplished, at least in part, by pigment regulation. Indeed, our data typically shows increases in $F_{\mathrm{v}}{ }^{\prime} / F_{\mathrm{m}}{ }^{\prime}$ that are paired with increased chlorophyll, and increased chlorophyll with decreased PAR. Phycobilins seemed to show the same relationship, though were only significant with EC samples for phycocyanin. Cyanobacteria have the ability to respond to changes in light via state transitions, which involves changing the distribution of light energy from physo- bilisomes to PSII and PSI. Phycobilisomes are highly mobile and unstable, and therefore transient - this allows for changes in the distribution of phycobilisome complexes associated with PSII and PSI. It has been shown that this phenomenon is significant for cyanobacteria in low light (Mullineaux \& EmlynJones 2005), and therefore likely plays a role in light acclimation for the cyanobacteria at EC and MI (Campbell et al. 1998, Perkins et al. 2010).

Seasonality in chlorophyll is a well-known phenomenon in phytoplankton communities (Niebauer et al. 1995) and has been studied in cyanobacterial mats as well (Pinckney et al. 1995). However, most studies use chlorophyll as a measure of oxygenic phototrophic biomass by measuring chlorophyll per unit area. We opted to measure chlorophyll per unit dry mass to estimate cellular chlorophyll content as we were interested in cyanobacterial activity. Although chlorophyll per unit dry mass is related to the production of new biomass, it is more closely related to photophysiology. This allowed a measure that estimated the amount of chlorophyll that was independent of the size of the sample collected. While the top purple layer of the cyanobacterial mat was dominated by Cyanobacteria, it was not possible to ensure that other organisms or small detrital particles were not present in the samples, which would falsely decrease the chlorophyll concentration.

In linear regression analyses, chlorophyll showed a positive relationship with PAR at EC and MIS but not

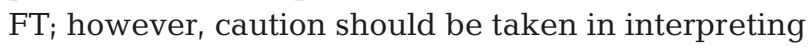
regression data from MIS due to low sample sizes. It is possible that cleaning of the fountain may have interfered with chlorophyll measurements by interrupting biofilm development. Regardless, these data seem to again support the idea that chlorophyll levels are low during times of high PAR to avoid cellular damage from excess energy, while chlorophyll expression increases with decreasing light levels at the other sites as PAR is not excessively high. So as PAR increases, pigments decrease, and $F_{\mathrm{v}}{ }^{\prime} / F_{\mathrm{m}}{ }^{\prime}$ negatively correlates with PAR. This relationship is theoretically maintained by controlling pigment concentration. This was true for EC only, although the p-value for FT is arguably biologically significant (0.0552). It is possible that this relationship did not hold at MIS simply due to such a low sample size $(\mathrm{n}=$ 4). Another explanation could be the greatly diminished role of variability in PAR reaching MIS mats (only $\pm 9 \mu \mathrm{mol}$ photons $\mathrm{s}^{-1} \mathrm{~m}^{-2}$ ). This represents a range of 0 (darkness) to just over $100 \mu$ mol photons $\mathrm{s}^{-1} \mathrm{~m}^{-2}$, and likely even less during the darker months - this is a much smaller range than meas- 

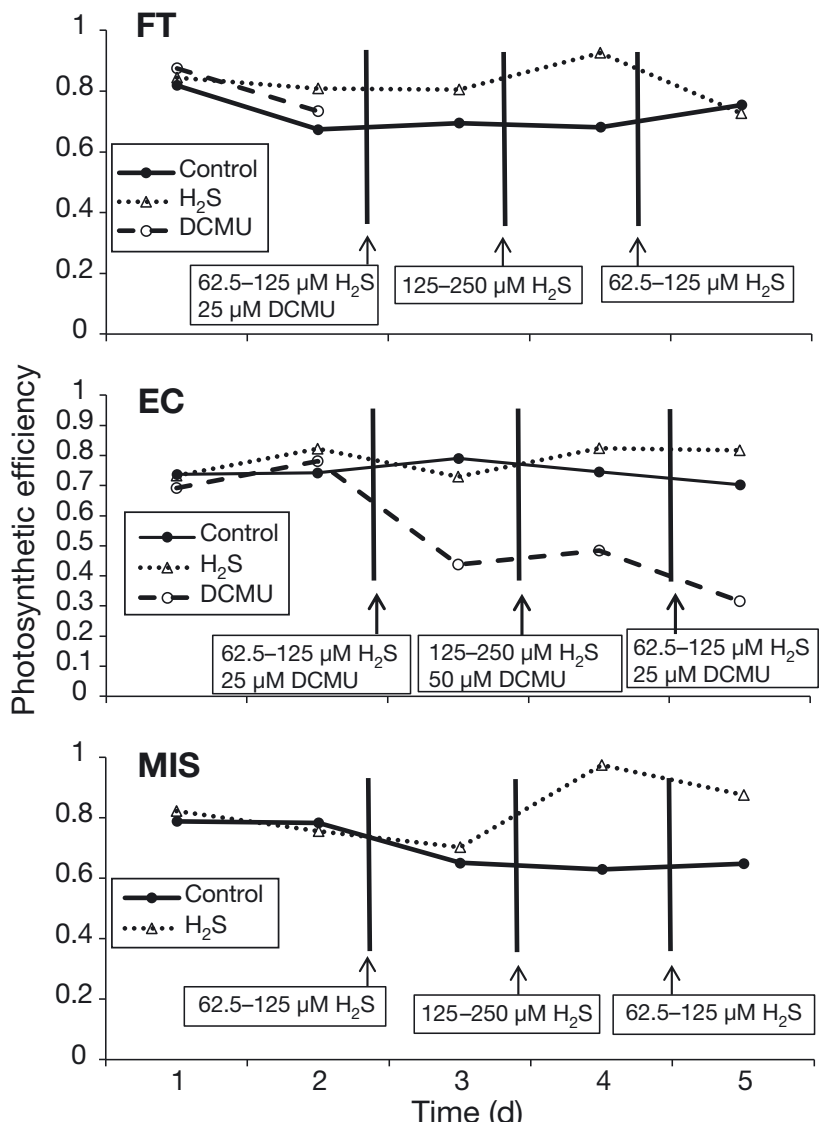

Fig. 6. Time series of addition of increased inhibitor concentrations for samples from all 3 study sites: El Cajon (EC), the Fountain (FT), and Middle Island Sinkhole (MIS). Two baseline, non-affected time points ('control', referring to time 0 ; before the start of the experiment) were measured before addition of inhibitors. Later time points for DCMU are missing as samples were too few after many cultures died; no DCMU treatments are presented for MIS as samples in this group were too few after cultures died

ured at the other sites. In that sense, MIS has a significantly diminished effect of seasonal PAR, so it is not surprising that yield would not show a positive or negative relationship with PAR.

PAR measurements were essentially instantaneous and thus highly susceptible to effects of cloud cover, time of day, and other possible factors. Weather station PAR data was used as an alternate method of measuring PAR to minimize these variables. However, no statistical differences were detected in regression analyses between the use of our LiCor readings and the local weather station PAR data (Table 6). The benefit of the weather station data is that PAR for the whole day could be averaged to get a better value for the level of PAR at that point in the season, while the obvious disadvantage is the geographic distance from the actual sites-roughly $113 \mathrm{~km}$.
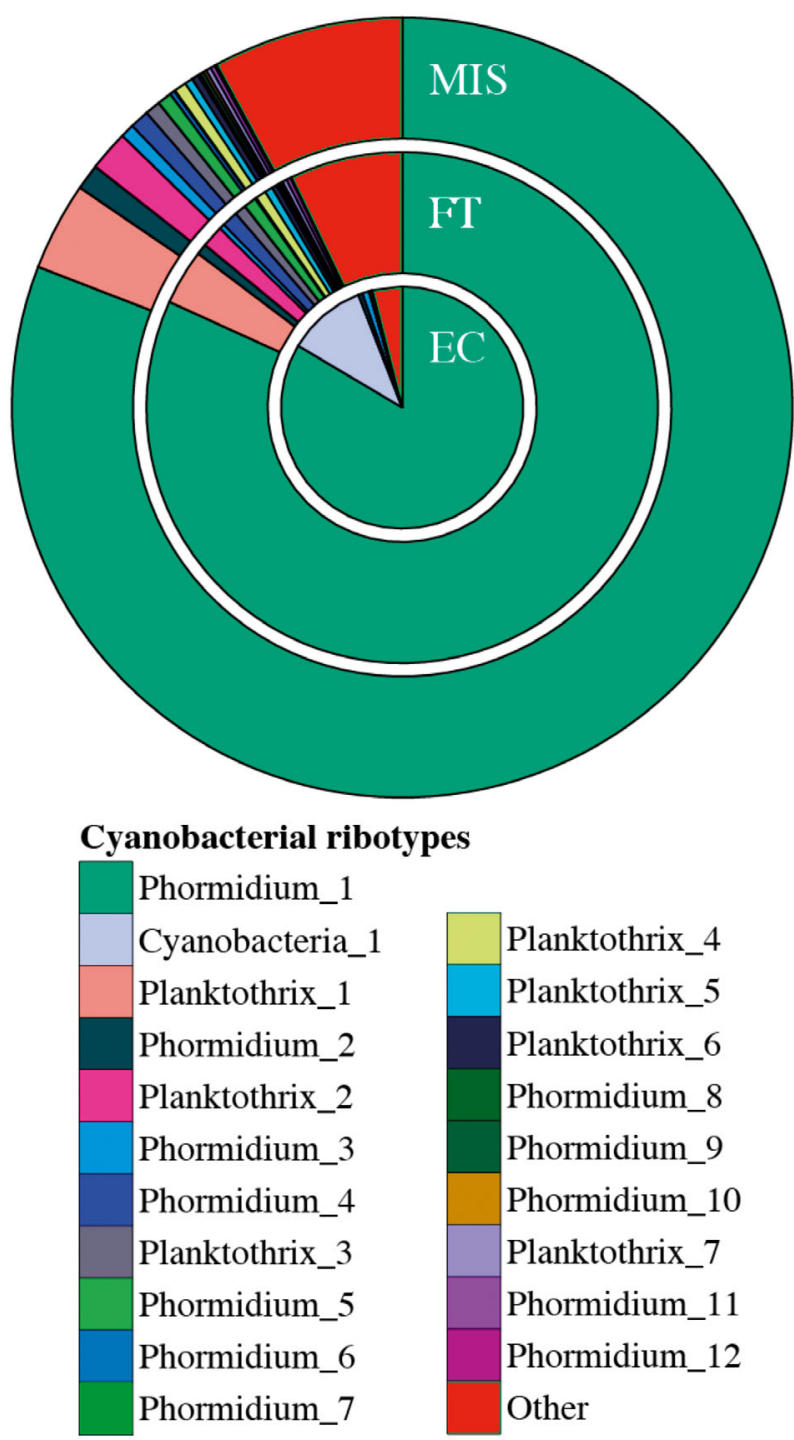

Fig. 7. Relative abundance of major cyanobacterial ribotypes at the 3 study sites: El Cajon (EC), the Fountain (FT), and Middle Island Sinkhole (MIS).

\section{Physical differences of study sites influence mat photophysiology}

Comparing biological parameters between sites for photosynthetic yield and pigment concentration led to only one statistical difference - chlorophyll at FT (for the summer and year-long average). This likely stems from the physical conditions of FT and the variability of PAR, discussed above. Higher levels of chlorophyll pigmentation would potentially cause photoinhibition above optimal levels of PAR, and thus chlorophyll concentrations are considerably lower than at EC and MIS for both summer and winter. It is also possible that this statistical finding was 
due to non-cyanobacterial and non-photosynthetic growth that was more prevalent during the warm period.

The physical habitat at each site alters the amount of PAR. For example, $F_{\mathrm{v}}{ }^{\prime} / F_{\mathrm{m}}{ }^{\prime}$ was similar at all sites despite a vast range of PAR reaching the mats at each location. Many EC samples were collected from plants. Dense cyanobacterial growth coated the plants from the base to water surface. At the water surface, large areas of detritus were observed floating (motionless), and the cyanobacterial growth connected from the plants to the underside of the detrital rafts. Growth was most dense on the plants and the underside of the floating rafts - all relatively shaded areas. These conditions simultaneously act to decrease the incident angle of oncoming PAR for cyanobacteria on the plants, and cyanobacterial growth on these substrates may promote self-shading. The cyanobacteria can take advantage of these physical features over small scales by rapid phototactic motility (Biddanda et al. 2012, 2015). Oxygen is available for those cyanobacteria located on or even near these plants (perhaps in only small amounts), which provides some benefit in the form of respiration. The extent and benefit of this effect is unknown, however, and would be a worthwhile study. In terms of PAR, EC and MIS may be more similar in their light climates than previously realized because EC cyanobacteria can potentially relocate to areas of lower light, or at least preferentially grow in areas of lower light. MIS receives low light due to depth, while cyanobacteria in $\mathrm{EC}$ are able to relocate along microscales to optimize light harvesting. Considering that most cyanobacterial growth at EC is found in shaded areas, it seems as if the incident PAR is much higher than needed. PAR and chlorophyll data collected at a more micro-scale would be needed to confirm this hypothesis.

Cyanobacteria at FT are exposed to high, direct PAR and must also maintain adhesion to the fountain bottom. The high water flow would wash mats down the drain if they were not clinging tightly to the bottom. This likely requires extra energy for cellular adhesive material. These reasons may also contribute to the visibly different appearance of FT mats compared to EC and MIS mats. FT mats are typically a browner, orange color instead of the vivid purple seen at the other sites (Fig. 2). These samples seemed more purple during the winter, almost appearing scorched during the high-light summer. The presence of carotenoids and other UV absorbing compounds such as microsporin-like amino acids (MAA) may also help with warding off excess energy absorption as well as contributing to the darker appearance, though MAAs mainly absorb in the UV range so likely play a minor role. Similar color changes have been observed in other mat-forming aquatic cyanobacteria. Peter et al. (2010) found that chlorosis occurred due to both nitrogen deficiency and excess light, attesting to the possibility that the yellowing of filaments could be a result of high PAR. Similar color changes were observed in the fall 2015 pigment extraction under high-light conditions without access to fresh groundwater for several days (see Fig. S4 in the Supplement).

Strong evidence has been presented to show significant photosynthetic inhibition by DCMU, but not by $\mathrm{H}_{2} \mathrm{~S}$. The concentration of in situ $\mathrm{H}_{2} \mathrm{~S}$ is between 100 and $250 \mu \mathrm{M}$ (D. Costello \& G. Dick pers. comm.), which is within the range of concentrations used in these experiments, so photosynthetic inhibition does not occur at levels of $\mathrm{H}_{2} \mathrm{~S}$ present in these sinkholes. Both chemicals used were PSII inhibitors, but some organisms, including those studied here, have strategies to tolerate $\mathrm{H}_{2} \mathrm{~S}$. DCMU inhibits photosynthesis by binding to and blocking the plastoquinone binding site of PSII, which then blocks passage of electrons from PSII to the electron transport chain. The most common adaptation to sulfide is through the activation of sulfide-dependent PSI, which often allows concurrent anoxygenic and oxygenic photosynthesis, or at least acts as a detoxifying mechanism to allow continuation of PSII operation. Still others will simply convert to a purely anoxygenic form of photosynthesis, allowing stoppage of PSII.

Sulfide tolerance in cyanobacteria has been categorized into 4 broad groups: (1) sulfide sensitive (oxygenic photosynthesis inhibited at $<75 \mu \mathrm{M}$ ); (2) oxygenic photosynthetic cyanobacteria incapable of anoxygenic photosynthesis that are able to tolerate significant levels of sulfide (up to $350 \mu \mathrm{M}$ ), and oxygenic photosynthesis is even stimulated over certain ranges of sulfide; (3) simultaneous sulfide-insensitive oxygenic photosynthesis (with low carbon assimilation activity measured up to levels of $1000 \mu \mathrm{M}$ ) with sulfide-driven anoxygenic photosynthesis; and (4) asynchronous oxygenic and anoxygenic photosynthesis where PSII activity is fully inhibited at $80 \mu \mathrm{M}$, and anoxygenic photosynthesis could operate between 200 and $1000 \mu \mathrm{M}$ (Cohen et al. 1986, Minz et al. 1999).

The mats found in these 3 sites are likely a combination of 2 different sulfide physiology groups described above. Our observation that photosyn- 
thetic yield was inhibited by DCMU, but not sulfide, suggests that the microbial mats are primarily type 2 (and not type 4 ) sulfide tolerant. It is known that sulfide-driven anoxygenic photosynthesis occurs, and Voorhies et al. (2012) found negligible production of net oxygen in intact cores - this does not exclude the possibility of group 2 cyanobacteria because the oxygen is likely used through concurrent respiratory processes in the mat (Voorhies et al. 2012). From the knowledge that anoxygenic photosynthesis occurs in the mats, we would predict that type 3 sulfide tolerant physiology is present, though we were unable to measure anoxygenic photosynthesis in the present study as the Diving-PAM only measures PSII activity (Voorhies et al. 2012). Mats from all 3 sites were treated with and were able to tolerate sulfide levels 10 times higher than that found in the Zodletone sulfur spring, concurrent with previous findings that the mats use sulfide for anoxygenic photosynthesis (Bühring et al. 2011, Voorhies et al. 2012). A similar Oscillatoria-like cyanobacteria was described in Lake Arcas that performed sulfidedependent anoxygenic photosynthesis with relatively sulfide tolerant oxygenic photosynthesis (Camacho 1996). Further, differential phycobilin synthesis was found in that study, though not in our experiments. The ability for simultaneous sulfide and oxygen tolerance would have been a key factor for survival during the period of several billion years in which oxygen in Earth's atmosphere gradually increased. Further, the simultaneous presence of both anoxygenic and oxygenic photosynthesis is likely a factor that prolonged the low-oxygen conditions during the Proterozoic Eon, 2.5 BYA (Johnston et al. 2009, Falkowski 2015).

Versatility of the photosynthetic community in these varying light regimes may be linked to community composition. Members of Cyanobacteria are highly abundant at all 3 sites, with one ribotype consistently constituting over $80 \%$ of the cyanobacteria. This ribotype is identical over the 253 DNA bases sequenced to the dominant filamentous Phormidium sp. in previous studies (Voorhies et al. 2012, Biddanda et al. 2012). This similar community composition across sites indicates that the cyanobacteria contain behavioral and/or physiological strategies to maintain similar photosynthetic yields across widely varying PAR. Light-influenced motility may enable the cyanobacteria to optimize their position with regard to light regime. For example, the cyanobacterial community in EC was preferentially attached below plants and detrital rafts, re- ceiving a different angle of radiation. The cyanobacterial assemblage in these natural environments, dominated by similar Phormidium sp., has strong phototactic responses (Biddanda et al. 2015). On the other hand, cyanobacteria at FT were frequently in direct, high irradiance, with minimal options for phototactic or photoaverse movement. Instead, to avoid oxidative and light stress, FT Phormidium and the other cyanobacterial ribotypes may rely upon modulating the abundance of chlorophyll, carotenoids, and phycobilins (e.g. orange carotenoids in the summer, phycobilins in the winter). The dominant cyanobacteria contain genes for breakdown of phycobilisomes, consistent with regulation of phycobilisome content for optimization of photosynthetic performance and/or nitrogen homeostasis (de Vries \& Ripley 2014). Associated viruses also contain this gene, suggesting that community interactions can also influence pigment content (Voorhies et al. 2016).

\section{CONCLUSIONS}

This study examined 3 geographically separate and isolated locations bathed in compositionally identical ground water that are characterized by genetically similar microbial communities growing under contrasting light regimes. All contain stable, persistent groundwater inputs that provide constant chemical conditions. PAR was found to be an important driver of chlorophyll levels at the 2 lower light locations, and the high-light site contained significantly lower levels of chlorophyll to counteract the excessively high PAR. The difference in pigmentation did not significantly affect the photosynthetic yield between sites - the changes in pigmentation likely helps adjust and maintain yield when faced with varying PAR. An apparent seasonal trend was seen most strongly in photosynthetic yield within each site - the winter (low PAR) had significantly higher yield than the summer (high PAR). Molecular analyses characterized similarities in cyanobacterial community composition, suggesting metabolic versatility. Lab studies showed that these communities are able to maintain oxygenic photosynthesis despite relatively high levels of ambient hydrogen sulfide. Such results highlight rare, yet easily accessible, modern lacustrine ecosystems that contain cyanobacterial life with versatile physiologies invaluable to our understanding of Earth's history and biodiversity (Biddanda et al. 2012, Falkowski 2015). 
Acknowledgements. We are grateful to Ralph Smith (University of Waterloo), who graciously loaned us the DivingPAM used in this research. We thank the dive team, comprising NOAA's Thunder Bay National Marine Sanctuary's Russ Green, Tane Casserly, Joe Hoyt, Stephanie Gandulla and Wayne Lusardi, and University of California-Davis's Taylor Mackey for field support with underwater mat sampling, measurements and photography. This study was supported by NSF EAGER grants EAR 1035957 to B.A.B. and EAR 1035955 to G.J.D. M.J.S. was supported on a Grand Valley State University Presidential Grant, and a Michigan Space Grant Consortium Graduate Fellowship from NASA.

\section{LITERATURE CITED}

Abdala-Díaz RT, Cabello-Pasini A, Pérez-Rodríguez E, Conde Álvarez RM, Figueroa FL (2006) Daily and seasonal variations of optimum quantum yield and phenolic compounds in Cystoseira tamariscifolia (Phaeophyta). Mar Biol 148:459-465

Auguie B (2015) gridExtra: miscellaneous functions for 'grid' graphics. $\mathrm{R}$ package version 2.0.0. http://CRAN.Rproject.org $/$ package $=$ gridExtra

Bennett A, Bogorad L (1973) Complementary chromatic adaptation in a filamentous blue-green alga. J Cell Biol 58(2):419-435

Biddanda BA, Nold SC, Ruberg SA, Kendall ST, Sander TG, Gray JJ (2009) Great Lakes sinkholes: a microbiogeochemical frontier. EOS Trans AGU 90:61-62

Biddanda B, Nold S, Dick G, Kendall S, Vail JH, Ruberg SA, Green CM (2012) Rock, water, microbes: underwater sinkholes in Lake Huron are habitats for ancient microbial life. Nat Educ Knowl 2:9

*Biddanda BA, McMillan AC, Long SA, Snider MJ, Weinke AD (2015) Seeking sunlight: rapid phototactic motility of filamentous mat-forming cyanobacteria optimize photosynthesis and enhance carbon burial in Lake Huron's submerged sinkholes. Front Microbiol 6:930

*Bühring SI, Sievert SM, Jonkers HM, Ertefai T, Elshahed MS, Krumholz LR, Hinrichs KU (2011) Insights into chemotaxic composition and carbon cycling of phototrophic communities in an artesian sulfur rich spring (Zoletone, Oklahoma, USA), a possible analog for ancient microbial mat systems. Geobiology 9:166-179

* Camacho A (1996) Adaptation to sulfide and to the underwater light field in three cyanobacterial isolates from Lake Arcas (Spain). FEMS Microbiol Ecol 21:293-301

Campbell D, Hurry V, Clarke A, Gustafsson P, Oquist G (1998) Chlorophyll fluorescence analysis of cyanobacterial photosynthesis and acclimation. Microbiol Mol Biol Rev 62:667-683

Cohen Y, Jorgensen B, Revsbech N, Poplawski R (1986) Adaptation to hydrogen sulfide of oxygenic and anoxygenic photosynthesis among cyanobacteria. Appl Environ Microbiol 51:398-407

Cosgrove J, Borowitzka M (2010) Chlorophyll fluorescence terminology: an introduction. In: Sugget D, Prasil O, Borowitzka $M$ (eds) Chlorophyll a fluorescence in aquatic sciences: methods and applications. Springer, New York, NY, p 1-17

de Vries A, Ripley BD (2014) ggdendro: tools for extracting dendrogram and tree diagram plot data for use with ggplot2. R package version 0.1-15. http://CRAN.R-project.org/package=ggdendro
Ehling-Schulz M, Scherer S (1999) UV protection in cyanobacteria. Eur J Phycol 34:329-338

Eren AM, Morrison HG, Lescault PJ, Reveillaud J, Vineis JH, Sogin ML (2015) Minimum entropy decomposition: unsupervised oligotyping for sensitive partitioning of high-throughput marker gene sequences. ISME J 9: 968-979

Evans R (2014) rje: miscellaneous useful functions. R package version 1.9. http://CRAN.R-project.org/ package $=$ rje

Falkowski PG (2015) Life's engines: how microbes made Earth habitable. Princeton University Press, Princeton, NJ

Falkowski P, Raven J (1997) Light absorption and energy transfer in the photosynthetic apparatus. In: Aquatic photosynthesis. Blackwell Science, Malden, MA, p 44-80

Falkowski PG, Fenchel T, DeLong EF (2008) The microbial engines that drive Earth's biogeochemical cycles. Science 320:1034-1039

Garcia-Pichel F, Belnap J, Neuer S, Schanz F (2003) Estimates of global cyanobacterial biomass and its distribution. Algol Stud 109:213-227

Gardner WC (1974) Middle Devonian stratigraphy and depositional environments in the Michigan basin. Special Paper No. 1, Michigan Basin Geological Society, Lansing, MI

Grannemann N, Hunt RF, Nicholas JR, Reilly TE, Winter TC (2000) The importance of ground water in the Great Lakes region. Water-Resources Investigations Report 00-4008, United States Geological Survey, Lansing, MI

Hawes I, Giles H, Doran P (2014) Estimating photosynthetic activity in microbial mats in an ice-covered Antarctic lake using automated oxygen microelectrode profiling and variable chlorophyll fluorescence. Limnol Oceanogr 59:674-688

Huot Y, Babin M (2010) Overview of fluorescence protocols: theory, basic concepts, and practice. In: Sugget D, Prasil O, Borowitzka M (eds) Chlorophyll a fluorescence in aquatic sciences: methods and applications. Springer, New York, NY, p 31-74

Huse SM, Dethlefsen L, Huber JA, Mark Welch M, Relman DA, Sogin ML (2008) Exploring microbial diversity and taxonomy using SSU rRNA hypervariable tag sequencing. PLOS Genet 4:e1000255

Johnston DT, Wolfe-Simon F, Pearson A, Knoll AH (2009) Anoxygenic photosynthesis modulated Proterozoic oxygen and sustained Earth's middle age. Proc Natl Acad Sci USA 106:16925-16929

Klatt CG, Wood JM, Rusch DB, Bateson MM and others (2011) Community ecology of hot spring cyanobacterial mats: predominant populations and their functional potential. ISME J 5:1262-1278

* Kozich JJ, Westcott SL, Baxter NT, Highlander SK, Schloss PD (2013) Development of a dual-index sequencing strategy and curation pipeline for analyzing amplicon sequence data on the MiSeq Illumina sequencing platform. Appl Environ Microbiol 79:5112-5120

* Lawrenz E, Fedewa E, Richardson T (2011) Extraction protocols for the quantification of phycobilins in aqueous phytoplankton extracts. J Appl Phycol 23:865-871

* Lorenzen C (1967) A determination of chlorophyll and pheo-pigments: spectrophotometric equations. Limnol Oceanogr 12:343-346 
Minz D, Fishbain S, Muyzer G, Cohen Y, Rittman BE, Stahl DA (1999) Unexpected population distribution in a microbial mat community: sulfate-reducing bacteria localized to the highly oxic chemicline in contrast to a eukaryotic preference for anoxia. Appl Environ Microbiol 65:4659-4665

Montechiaro F, Giordano M (2006) Effect of prolonged dark incubation on pigments and photosynthesis of the cavedwelling cyanobacterium Phormidium autumnale (Oscillatoriales, Cyanobacteria). Phycologia 45:704-710

Mullineaux CW, Emlyn-Jones D (2005) State-transitions: an example of acclimation to low-light stress. J Exp Bot 56: 389-393

Niebauer HJ, Alexander V, Henrichs S (1995) A time-series study of the spring bloom at the Bering Sea ice edge I. Physical processes, chlorophyll and nutrient chemistry. Cont Shelf Res 15:1859-1877

Nold SC, Bellecourt MJ, Kendall ST, Ruberg SA, Sanders TG, Val Klump J, Biddanda BA (2013) Underwater sinkhole sediments sequester Lake Huron's carbon. Biogeochemistry 115:235-250

Oksanen J, Guillaume B, Kindt R, Legendre P and others (2013) vegan: community ecology package. R package version 2.3-2

Olsson-Francis K, Cockell C (2010) Experimental methods for studying microbial survival in extraterrestrial environments. J Microbiol Methods 80:1-13

Oren A (1977) Quantum yields for oxygenic and anoxygenic photosynthesis in the cyanobacterium Oscillatoria limnetica. Proc Natl Acad Sci USA 74:2152-2156

Perkins R, Kromkamp J, Serodio J, Lavaud J and others (2010) The application of variable chlorophyll fluorescence to microphytobenthic biofilms. In: Sugget D, Prasil O, Borowitzka M (eds) Chlorophyll a fluorescence in aquatic sciences: methods and applications. Springer, New York, NY, p 237-275

Peter P, Sarma AP, Azeem ul Hasan MD, Murthy SDS (2010) Studies on the impact of nitrogen starvation on the photosynthetic pigments through spectral properties of the cyanobacterium Spirulina platensis: identification of target phycobiliprotein under nitrogen chlorosis. Bot Res Int 3:30-34

Pinckney J, Paerl HW, Fitzpatrick M (1995) Impacts of seasonality and nutrients on microbial mat community structure and function. Mar Ecol Prog Ser 123:207-216

Porra RJ, Thompson WA, Kriedemann PE (1989) Determination of accurate extinction coefficients and simultaneous equations for assaying chlorophylls a and b extracted with four different solvents: verification of the concentration of chlorophyll standards by atomic absorption spectroscopy. BBA 975:384-39

Editorial responsibility: Daniel Vaulot, Roscoff, France
R Core Team (2012) R: a language and environment for statistical computing. R Foundation for Statistical Computing, Vienna

Ralph P, Wilhelm C, Lavaud J, Jakob T, Petrou K, Kranz S (2010) Fluorescence as a tool to understand changes in photosynthetic electron flow regulation. In: Sugget D, Prasil O, Borowitzka M (eds) Chlorophyll a fluorescence in aquatic sciences: methods and applications. Springer, New York, NY, p 75-89

Ruberg SA, Kendall ST, Biddanda BA, Black T and others (2008) Observations of the Middle Island sinkhole in Lake Huron: a unique hydrologic and glacial creation of 400 million years. Mar Technol Soc J 42:12-21

Sanders TG Jr, Biddanda BA, Stricker CA, Nold SC (2011) Benthic macroinvertebrate and fish communities in Lake Huron are linked to submerged groundwater vents. Aquat Biol 12:1-11

Schloss PD, Westcott SL, Ryabin T, Hall JR and others (2009) Introducing mothur: open-source, platform-independent, community-supported software for describing and comparing microbial communities. Appl Environ Microbiol 75:7537-7541

Voorhies AA, Biddanda BA, Kendall ST, Jain S and others (2012) Cyanobacterial life at low $\mathrm{O}_{2}$ : community genomics and function reveal metabolic versatility and extremely low diversity in a Great Lakes sinkhole mat. Geobiology 10:250-267

Voorhies AA, Eisenlord SD, Marcus DN, Duhaime MB, Cavalcoli JD, Biddanda BA, Dick GJ (2016) Ecological and genetic interactions between cyanobacteria and viruses in a low $-\mathrm{O}_{2}$ mat community inferred through metagenomics and metatranscriptomics. Environ Microbiol 18:358-371

Warner M, Chilcoat G, McFarland F, Fitt W (2002) Seasonal fluctuations in the photosynthetic capacity of photosystem II in symbiotic dinoflagellates in the Caribbean reefbuilding coral Montastraea. Mar Biol 141:31-38

*Warnes GR, Bolker B, Lumley T (2015) gtools: various R programming tools. $\mathrm{R}$ package version 3.5.0. http: //CRAN.Rproject.org/package=gtools

Castenholz RW, Garcia-Pichel F (2012) Cyanobacterial responses to UV radiation. In: Whitton BA (ed) Ecology of Cyanobacteria II: their diversity in space and time. Springer, Dordrecht, p 481-502

*Wickham H (2007) Reshaping data with the reshape package. J Stat Softw 21(12)

Wickham H (2009) ggplot2: elegant graphics for data analysis. Springer, New York, NY

Wickham H (2011) The split-apply-combine strategy for data analysis. J Stat Softw 40:1. www.jstatsoft.org/ v40/i01/

Submitted: June 27, 2016; Accepted: December 10, 2016

Proofs received from author(s): March 10, 2017 